\title{
Effects of curcumin on ovarian ischemia-reperfusion injury in a rat model
}

\author{
AYLA ESER $^{1}$, DENIZ HIZLI ${ }^{1}$, HACER HALTAS $^{2}$, MEHMET NAMUSLU $^{3}$, \\ AYDIN KOSUS $^{1}$, NERMIN KOSUS ${ }^{1}$ and HASAN KAFALI ${ }^{4}$ \\ Departments of ${ }^{1}$ Obstetrics and Gynecology, ${ }^{2}$ Pathology and ${ }^{3}$ Biochemistry, Turgut Ozal University School of Medicine, \\ 06510 Ankara; ${ }^{4}$ Department of Obstetrics and Gynecology, Gazi University Medical School, 06500 Ankara, Turkey
}

Received March 31, 2015; Accepted June 10, 2015

DOI: $10.3892 /$ br.2015.515

\begin{abstract}
Ischemia-reperfusion injury is a significant problem following reperfusion treatment for ovarian torsion. It is generally caused by reactive oxygen species-induced damage. Antioxidant agents, such as curcumin, may protect ovaries from this adverse effect. The aim of the present randomized, controlled study was to evaluate the short-term protective effect of curcumin on a rat model of ovarian ischemia-reperfusion injury. A total of 30 female Wistar albino rats, weighing 160-230 g, were divided into 2 groups depending upon the time of unilateral, left ovary ischemia/reperfusion (group 1, $2 \mathrm{~h}$ ischemia/2 $\mathrm{h}$ reperfusion and group $2,4 \mathrm{~h}$ ischemia/4 h reperfusion). These groups were subdivided into 3 subgroups (sham, control and curcumin). The sham subgroups were not subjected to ischemia/reperfusion. Control and curcumin subgroups were performed under ischemia for $2 \mathrm{~h}$ plus $2 \mathrm{~h}$ reperfusion or $4 \mathrm{~h}$ ischemia plus $4 \mathrm{~h}$ reperfusion. Curcumin, $200 \mathrm{mg} / \mathrm{kg}$, was intraperitoneally administered simultaneously with reperfusion to the curcumin subgroups. Serum nitric oxide (NO), NO synthase (NOS), xanthine oxidase (XO), total antioxidant status (TAS), total oxidant status (TOS) and histological scores were measured and compared between subgroups. For group 1, no significant differences were observed between NO, NOS, XO, TAS or TOS. The left ovary histological grade was significantly higher in the control and curcumin subgroups compared with the sham subgroup $(\mathrm{P}=0.036)$. For group 2 , TOS was significantly higher in the control group compared with the sham and curcumin groups $(\mathrm{P}=0.023)$. However, TAS was also significantly higher in the control subgroup compared
\end{abstract}

Correspondence to: Dr Ayla Eser, Department of Obstetrics and Gynecology, Turgut Ozal University School of Medicine, 57 Ciftlik Caddesi, 06510 Ankara, Turkey

E-mail: aylaacar76@yahoo.com.tr

Abbreviations: NO, nitric oxide; NOS, nitric oxide synthase; XO, xanthine oxidase; TAS, total antioxidant status; TOS, total oxidant status; ROS, reactive oxygen species; LO, left ovary; RO, right ovary

Key words: curcumin, ischemia-perfusion injury, ovarian ischemia, oxidative stress, total oxidant status with the other 2 subgroups $(\mathrm{P}=0.005)$. Left ovary histological grade was significantly higher in the control and curcumin subgroups compared with the sham subgroup ( $\mathrm{P}=0.038)$. No significant differences were observed between NO, NOS or XO between the group 2 subgroups. The results showed that curcumin exerted no major significant protective effect on ischemia-reperfusion injury in the rat ovary.

\section{Introduction}

Ovarian torsion, often termed adnexal torsion, is the fifth most common gynecological emergency condition in women (1). It is initially associated with reduced venous ovarian blood flow, and it can progress to restricted arterial blood flow and ischemia and infarction $(2,3)$. However, the diagnosis and treatment is often delayed due to the non-specificity of the symptoms (2). The aim of ischemia treatment is not only to achieve blood flow but also to restore tissue reperfusion. However, reperfusion injury, referring to the microvascular and parenchymal cell dysfunction of ischemic organs, can occur during the restoration of tissue reperfusion following ischemia (4-7). This reperfusion injury is mediated by reactive oxygen species (ROS) generated via lipid peroxidation, promoting the release of inflammatory agents $(7,8)$. Thus, if the impact of these detrimental ROS could be limited, ischemia-reperfusion injury could be avoided or reduced.

Used as a pigment, spice and additive in the majority of Asian countries, curcumin is extracted from a perennial herbaceous plant known as Curcuma Longa (9). A number of studies have revealed that, similar to the other flavonoids, curcumin has significant antioxidant and anti-inflammatory properties (10-12). Curcumin scavenges ROS, reducing free radical injury to the tissues $(9,13)$.

Curcumin has recently been implicated in the reduction of tissue damage caused by reperfusion injury in multiple organs in rat models. These include cardiac dysfunction caused by renal ischemia and reperfusion (14), lung, renal and cardiac damage in an abdominal aorta ischemia-reperfusion injury model (15) and neuroprotection in a cerebral ischemia-reperfusion injury model (16). These studies cite the ROS-scavenging and anti-inflammatory properties of curcumin as key to its protective effects. One recent study has also shown a protective effect of curcumin against ovarian reperfusion injury in 
rats (17). This is consistent with other rat studies indicating a protective effect of ROS-scavenging and anti-inflammatory agents in ovarian reperfusion injury, such as etoricoxib (18) and hesperidin (19). Additionally, another flavonoid, quercetin, has also been shown to have protective effects against apoptosis and ischemia-modified albumin levels in a rat model of ovarian ischemia-reperfusion injury, thus protecting against tissue injury (20).

Taken together, there is evidence of a role for curcumin in the protection against tissue damage in multiple organs in rats and evidence supporting a role for ROS-scavenging and anti-inflammatory agents, including the flavonoids curcumin and quercetin in ovarian reperfusion injury. However, as only one single study supporting the protective effect of curcumin against ovarian reperfusion injury in rats is available (17), there is a necessity to further explore the effect of curcumin on rats ovaries prior to, for example, the consideration of any future human applications.

\section{Materials and methods}

Characteristics of rat treatment groups and surgical procedures. A total of 30 female Wistar albino rats, weighing 160-230 g, were used in the study. The study protocol was approved by the Gazi University Ethics Committee for Animal Research (GÜADEK; Ankara, Turkey). The rats were kept for $\geq 7$ days under appropriate conditions of temperature/humidity and a 12-h light cycle while being provided sufficient water and feed. The rats were randomly divided into 2 main groups, groups 1 and 2, based on the duration of ischemia/perfusion ( 2 or $4 \mathrm{~h}$ each) with 15 rats in each and 6 subgroups, I-VI, based on the presence or absence of curcumin during perfusion (Table I). A curcumin dosage of $200 \mathrm{mg} / \mathrm{kg}$ was consistent in order of magnitude with other studies of ischemia/perfusion $(17,21)$.

Each rat was weighed and anesthetized with $50 \mathrm{mg} / \mathrm{kg}$ intramuscular ketamine hydrochloride (Ketalar, Eczacibasi, Istanbul, Turkey) and $10 \mathrm{mg} / \mathrm{kg}$ xylazine hydrochloride (Rompun, Bayer Türk Ilaç Ltd., Istanbul, Turkey). Following preoperative sterilization, a longitudinal incision of $2.5 \mathrm{~cm}$ was performed in the midline area of the lower abdomen. Treatment and surgical procedures were carried out as in Table I. Rats were subsequently sacrificed by intracardiac blood-letting. Blood samples were centrifuged for $10 \mathrm{~min}$ at 2,862 $\mathrm{x} \mathrm{g}$ and sera was stored in a freezer at $-20^{\circ} \mathrm{C}$ for biochemical analysis. The ovarian tissues were maintained in $10 \%$ formaldehyde solution for histopathological examination. The investigators carrying out the biochemical and histological analyses were blinded to the randomization until the end of the study.

Histological evaluation. Paraffin-embedded ovarian tissue samples were stained with hematoxylin and eosin (H\&E). For quantitative measurements, sections were analyzed and photographed by a light photomicroscope (Nikon Eclipse 80i; Nikon, Tokyo, Japan) in a minimum of 5 microscopic fields. The histological sections were assessed for interstitial edema, vascular congestion, hemorrhage and polymorphonuclear leukocyte (PMN) infiltration; the assessor was blinded to the treatment protocol. Each specimen was scored on a scale ranging from 1 to 4 (1, none; 2 , mild; 3 , moderate; 4 , severe) as follows $(21,22)$ : Grade 1, mild edema/mild vascular congestion/no hemorrhage/no PMN; grade 2, moderate edema/moderate vascular congestion/no hemorrhage/no PMN; grade 3 , severe edema/severe vascular congestion/minimal hemorrhage/minimal PMN; and grade 4, severe edema/severe vascular congestion/severe hemorrhage/severe PMN.

Biochemical analyses. The following biochemical analyses were carried out: Nitric oxide (NO) levels and NO synthase (NOS) and xanthine oxidase (XO) enzyme activities were measured in serum by spectrophotometry (UV-1700; Shimadzu Corporation, Kyoto, Japan).

Total antioxidant status (TAS) levels in urine were measured using an automated measurement method, as described previously (23). A colored 2,2'-azinobis-(3-ethylbenzothiazoline-6-sulfonic acid) radical cation substrate was employed, which was decolorized by antioxidants according to their concentrations and antioxidant capacities. This change in color was measured as a change in absorbance at $660 \mathrm{~nm}$. This process is applied to an automated analyzer (Cobas Mira Plus; Roche Diagnostics GmbH, Mannheim, Germany) and the assay was calibrated with Trolox. The results are expressed as millimoles of Trolox equivalent/liter (24).

TOS levels in urine samples were determined using an automated colorimetric measurement method as described previously (25). The assay was based on the oxidation of ferrous ion to ferric ion in the presence of oxidant species in the acidic medium and the measurement of the ferric ion by xylenol orange. This change in color was measured as a change in absorbance at $660 \mathrm{~nm}$. The oxidation reaction of the assay was enhanced and precipitation of proteins was prevented. The method was applied to an automated analyzer (Cobas Mira Plus; Roche Diagnostics $\mathrm{GmbH}$ ), which was calibrated with hydrogen peroxide $\left(\mathrm{H}_{2} \mathrm{O}_{2}\right)$ and the analytical performance characteristics of the assay were determined. The results are expressed as millimoles $\mathrm{H}_{2} \mathrm{O}_{2}$ equivalent per liter (24).

The oxidative stress index (OSI) was calculated as the percentage ratio of total oxidant status (TOS) level to total antioxidant capacity (TAC) level according to the following formula: OSI (arbitrary unit) $=$ TOS (micromolar $\mathrm{H}_{2} \mathrm{O}_{2}$ equivalent/liter)/TAC (micromolar trolox equivalent/liter) (11).

NO and NOS were measured by the method based on the diazotization of sulfanilic acid by $\mathrm{NO}$ at acid $\mathrm{pH}$ and subsequent coupling to $N$-(1-naphthyl)ethylenediamine) (Griess reaction) as described previously (26). As the nitrate anion does not give a diazotization reaction with sulfanilic acid, the samples were treated with cadmium (a reducing agent) to reduce nitrate anions into nitrite anions prior to the NO estimation (27). The results are expressed as $\mu \mathrm{mol} / \mathrm{mg}$ protein. The total NOS activity (IU/ml) method was based on the Griess reaction (26).

$\mathrm{XO}$ enzyme activity was determined by measuring the optical density of uric acid, which is formed from xanthine by xanthine oxidase, at $293 \mathrm{~nm}$ as described previously (28).

Statistical analysis. Using the SPSS program (SPSS 16.0 for windows; SPSS, Inc., Chicago, IL, USA), the distribution of data was checked graphically and by the Shapiro-Wilk test. In the representation of continual data, mean \pm standard deviation was used in the normally distributed quantitative parameter. 
Table I. Summary of treatment groups and surgical procedures.

$\begin{array}{ll}\text { Treatment groups } & \text { Surgical procedures }\end{array}$

Group 1 ( $2 \mathrm{~h}$ ischemia $+2 \mathrm{~h}$ reperfusion)

Subgroup I, $\mathrm{n}=3$

Subgroup II, $\mathrm{n}=6$

Subgroup III, $\mathrm{n}=6$

Group 2 (4 h ischemia+4 h reperfusion)

Subgroup IV, $\mathrm{n}=3$

Subgroup V, n=6

Subgroup VI, n=6
Sham (abdominal incision with no ischemia/perfusion). Following laparotomy, the abdominal incision was covered with surgical gauze sluiced with sterile saline solution for $4 \mathrm{~h}$. The two ovaries were surgically removed. Bilateral oophorectomy was subsequently performed on all the rats

Control (abdominal incision with ischemia/perfusion). Following laparotomy, the uterus and left ovary were visualised and a unilateral (left) complete ovarian ischemia model was obtained by locking the left ovarian vessels using a top knot style, with a two-sided atraumatic 1 silk suture for $2 \mathrm{~h}$ to create ischemic conditions

The ischemia silk sutures were subsequently opened and reperfusion occurred for another $2 \mathrm{~h}$. The abdominal incision was not closed by suturing, instead it was covered with surgical gauze sluiced with sterile saline solution during the procedure. Bilateral oophorectomy was subsequently performed on all the rats

Curcumin (abdominal incision with ischemia/perfusion and curcumin at $200 \mathrm{mg} / \mathrm{kg}$ ). As for subgroup II, except $200 \mathrm{mg} / \mathrm{kg}$ of intraperitoneal curcumin was administered simultaneously with perfusion based on the previous study that was proven in ischemia and perfusion (17). Bilateral oophorectomy was subsequently performed on all the rats

Sham (abdominal incision with no ischemia/perfusion). As for subgroup I, except the abdominal incision was covered with surgical gauze sluiced with sterile saline solution for $8 \mathrm{~h}$

Control (abdominal incision with ischemia/perfusion). Same as for subgroup II, except ischemia and perfusion were maintained for $4 \mathrm{~h}$ each

Curcumin (abdominal incision with ischemia/perfusion and curcumin at $200 \mathrm{mg} / \mathrm{kg}$ ). As for subgroup III, except ischemia and perfusion were maintained for $4 \mathrm{~h}$ each
Medians (minimum-maximum) are provided in non-normally distributed quantitative parameters and number and percentage are used to describe the categorical data. One-way analysis of variance with Bonferoni was used to compare the normally distributed data of 3 independent groups. Kruskal-Wallis test was used in the case of non-normally distributed data. Bonferoni revision Mann-Whitney U test was applied to dual comparisons on data that were established as significant by a result of the Kruskal-Wallis test. Correlation between parameters was measured by the Spearman correlation test. $\mathrm{P}<0.05$ was considered to indicate a statistically significant difference.

\section{Results}

Microscopic and macroscopic examination. Macroscopically, ischemic ovaries had a cherry-red color. Microscopic examination of $\mathrm{H} \& \mathrm{E}$-stained ovarian tissue samples in the control subgroups of groups 1 ( $2 \mathrm{~h}$ ischemia/ $2 \mathrm{~h}$ reperfusion) and 2 ( $4 \mathrm{~h}$ ischemia/4 $\mathrm{h}$ reperfusion) showed severe interstitial edema, severe vascular congestion, severe hemorrhage and acute infiltration by PMNs (Fig. 1). The curcumin subgroups (ischemia/reperfusion plus curcumin) also showed severe interstitial edema and severe vascular congestion, although with milder hemorrhage and PMN infiltration (Fig. 1). The sham subgroups (no ischemia/reperfusion) showed no evidence of tissue damage by any of the histological indicators (Fig. 1).
Biochemical analyses. Distribution of data from groups 1 and 2 are shown in Tables I and II, respectively. When any 2 different subgroups in group 1 were compared with each other by pairwise comparison, no statistically significant difference was established for NO, NOS, XO, TAS and TOS values (Table II). However, it was established that the left ovary (ischemic ovary; Table I) histological grade of the control and curcumin groups was significantly higher compared with the sham group $(\mathrm{P}=0.024$ and $\mathrm{P}=0.024$, respectively; $\mathrm{P}=0.036$ for comparison of the 3 subgroups, Table II). There was no statistically significant difference between the control and curcumin groups. There were also no significant differences established in terms of right ovary indicators (Table II).

When the group 2 subgroups were examined, it was shown that the TAS levels in the control group were significantly higher compared with those in the sham and curcumin groups $(\mathrm{P}=0.036$ and $\mathrm{P}=0.004$, respectively; $\mathrm{P}=0.005$ for comparison of the 3 groups, Table III). The lowest level was observed in the curcumin group (Table III). It was established that the TOS levels in the control group were also significantly higher compared with those in the sham and curcumin groups $(\mathrm{P}=0.048$ and $\mathrm{P}=0.009$, respectively; $\mathrm{P}=0.023$ for comparison of the 3 groups, Table III). The lowest level was again observed in the curcumin group (Table III). No statistically significant difference was identified between the subgroups in terms of NO, NOS and XO values (Table III). 
Table II. Distribution of the data for the group 1 subgroups.

\begin{tabular}{|c|c|c|c|c|}
\hline Variables & Sham & Control & Curcumin & P-value \\
\hline Rat, kg & $198.7 \pm 18.6$ & $192.0 \pm 29.9$ & $199.2 \pm 15.4$ & 0.848 \\
\hline LO grade & $1(1-2)$ & $3(2-4)$ & $3.5(2-4)$ & $0.036^{\mathrm{a}}$ \\
\hline RO grade & $1(1-2)$ & $1(1-1)$ & $1.5(1-2)$ & 0.160 \\
\hline $\mathrm{NO}, \mu \mathrm{mol} / \mathrm{mg}$ protein & $58.7(9.8-80.7)$ & $48.6(9.8-95.0)$ & $36.6(22.0-84.7)$ & 0.964 \\
\hline NOS, IU/ml & $3.5(3.3-6.6)$ & $3.2(2.4-9.9)$ & $5.6(2.8-9.8)$ & 0.269 \\
\hline $\mathrm{XO}, \mathrm{IU} / \mathrm{ml}$ & $0.9 \pm 0.1$ & $0.8 \pm 0.1$ & $0.8 \pm 0.3$ & 0.754 \\
\hline TAS, $\mu$ mol Trolox equivalent/l & $0.7(0.3-0.6)$ & $0.7(0.3-0.8)$ & $0.7(0.4-1.7)$ & 0.441 \\
\hline TOS, $\mu \mathrm{mol} \mathrm{H}_{2} \mathrm{O}_{2}$ equivalent/l & $1.8(1.8-2.8)$ & $3.5(1.5-6.3)$ & $2.9(2.0-4.7)$ & 0.283 \\
\hline
\end{tabular}

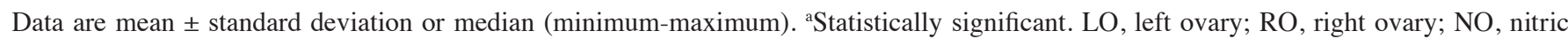
oxide; NOS, NO synthase; XO, xanthine oxidase; TAS, total antioxidant status; TOS, total oxidant status.

Table III. Distribution of the data for the group 2 subgroups.

\begin{tabular}{|c|c|c|c|c|}
\hline Variables & Sham & Control & Curcumin & P-value \\
\hline Rat, kg & $219.7 \pm 6.5$ & $217.8 \pm 16.2$ & $223.7 \pm 23.8$ & 0.874 \\
\hline LO grade & $1(1-2)$ & $4(0-4)$ & $4(3-4)$ & $0.038^{\mathrm{a}}$ \\
\hline RO grade & $1(1-1)$ & $1.5(0-2)$ & $2(1-2)$ & 0.254 \\
\hline $\mathrm{NO}, \mu \mathrm{mol} / \mathrm{mg}$ protein & $19.2(16.2-69.7)$ & $49.7(15.5-90.7)$ & $42.1(17.5-86.7)$ & 0.765 \\
\hline NOS, IU/ml & $3.4(3.3-7.0)$ & $4.5(3.3-14.5)$ & $10.3(3.7-15.3)$ & 0.163 \\
\hline $\mathrm{XO}, \mathrm{IU} / \mathrm{ml}$ & $0.8 \pm 0.2$ & $1.1 \pm 0.2$ & $0.8 \pm 0.3$ & 0.140 \\
\hline TAS, $\mu$ mol Trolox equivalent/l & $0.9(0.7-0.9)$ & $1.0(0.9-1.1)$ & $0.6(0.5-0.8)$ & $0.005^{\mathrm{a}}$ \\
\hline TOS, $\mu \mathrm{mol} \mathrm{H}_{2} \mathrm{O}_{2}$ equivalent/l & $3.6(1.5-4.3)$ & $6.6(3.9-8.2)$ & $2.9(1.5-5.0)$ & $0.023^{\mathrm{a}}$ \\
\hline
\end{tabular}

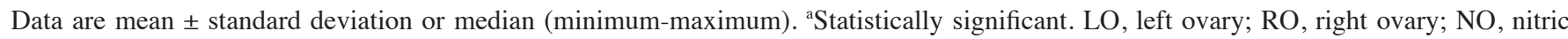
oxide; NOS, NO synthase; XO, xanthine oxidase; TAS, total antioxidant status; TOS, total oxidant status.

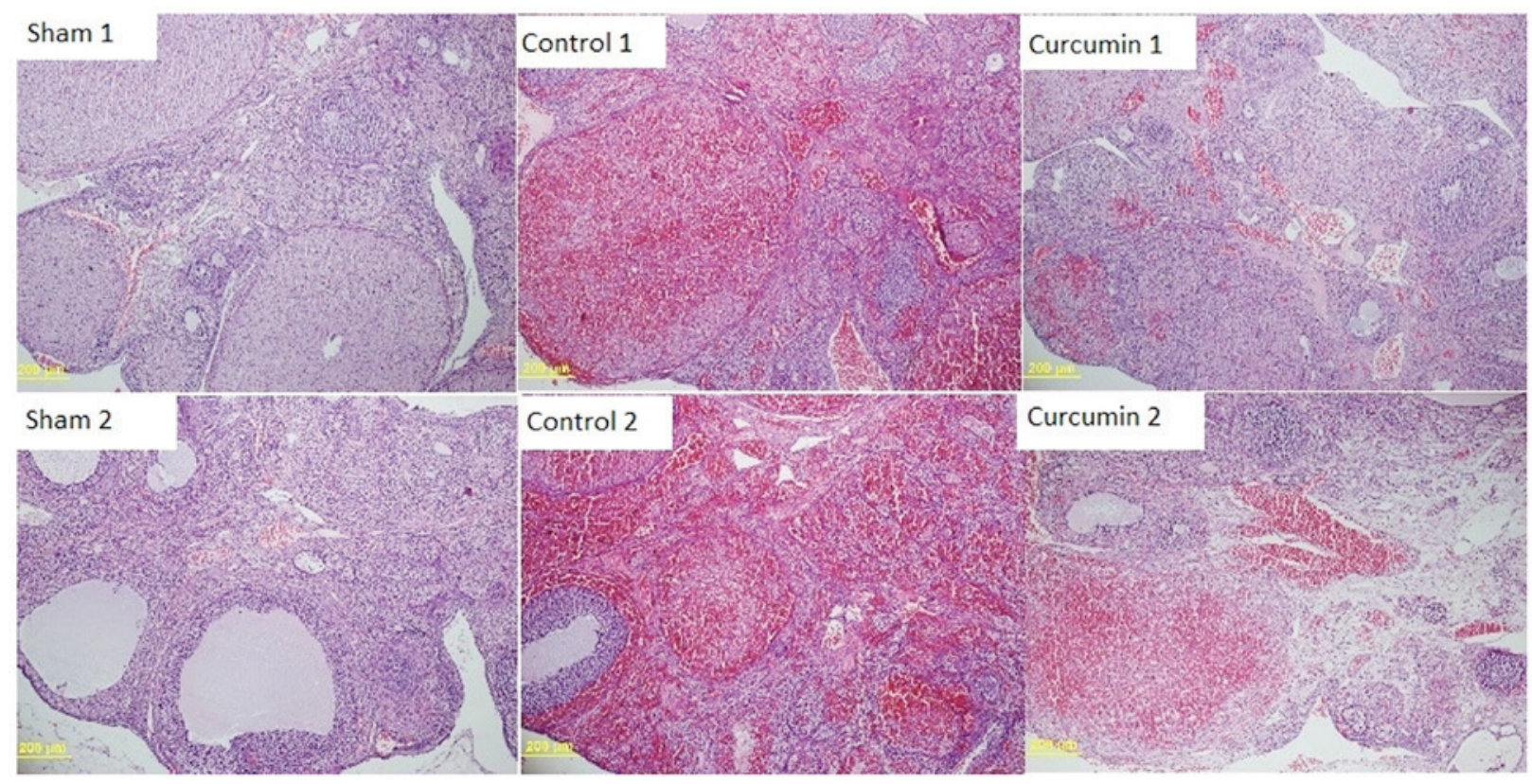

Figure 1. Histological evaluation of the rat ovary samples. Sham 1 and 2 are no ischemia/reperfusion samples; normal ovarian tissue structure [hematoxylin and eosin (H\&E, x100 magnification)]. Control 1 and 2 are ischemia/reperfusion only samples (2 and 4 h, respectively); ovarian sections containing severe edema, severe vascular congestion, severe haemorrhage and severe polymorphonuclear leukocyte (PMN) infiltration in ischemic rats (H\&E, $\mathrm{X} 100 \mathrm{magnifica-}$ tion). Curcumin 1 and 2 are ischemia/reperfusion (2 and 4 h, respectively) and curcumin-treated samples; ovarian sections containing severe edema, severe vascular congestion, mild haemorrhage and mild PMN infiltration in ischemic rats (H\&E, x100 magnification). 
Table IV. Comparison of the group 1 and 2 parameters.

\begin{tabular}{lccc}
\hline Variables & 2 h curcumin & 4 h curcumin & P-value \\
\hline Rat, kg & $199.2 \pm 15.4$ & $223.7 \pm 23.8$ & 0.060 \\
LO grade & $3.5(2-4)$ & $4(3-4)$ & 0.310 \\
RO grade & $1.5(1-2)$ & $2(1-2)$ & 0.699 \\
$\mathrm{NO}, \mu \mathrm{mol} / \mathrm{mg}$ protein & $36.6(22.0-84.7)$ & $42.1(17.5-86.7)$ & 0.818 \\
$\mathrm{NOS}, \mathrm{IU} / \mathrm{ml}$ & $5.6(2.8-9.8)$ & $10.3(3.7-15.3)$ & 0.065 \\
$\mathrm{XO}, \mathrm{IU} / \mathrm{ml}$ & $0.8 \pm 0.3$ & $0.8 \pm 0.3$ & 0.735 \\
$\mathrm{TAS} \mu \mathrm{mol} \mathrm{Trolox} \mathrm{equivalent/1}$ & $0.7(0.4-1.7)$ & $0.6(0.5-0.8)$ & 0.589 \\
$\mathrm{TOS}, \mu \mathrm{mol} \mathrm{H} \mathrm{O}_{2}$ equivalent/l & $2.9(2.0-4.7)$ & $2.9(1.5-5.0)$ & 0.818
\end{tabular}

Data are mean \pm standard deviation or median (minimum-maximum). LO, left ovary; RO, right ovary; NO, nitric oxide; NOS, NO synthase; XO, xanthine oxidase; TAS, total antioxidant status; TOS, total oxidant status.

Left ovary histological grade was also significantly higher in the curcumin subgroup compared with the sham subgroup $(\mathrm{P}=0.024)$ and was not significantly different from the control subgroup (Table III). There were no significant differences between subgroups in terms of any right ovary indicators (Table III).

When the 2 groups were compared, no statistically significant differences were observed between the curcumin subgroups of group 1 ( $2 \mathrm{~h}$ ischemia/2 h reperfusion) versus group 2 (4 h ischemia/4 h reperfusion) in terms of NO, NOS, XO, TAS, TOS and histological grades (Table IV).

\section{Discussion}

A recent study indicated a protective effect of curcumin in a rat model of bilateral ovarian ischemia/reperfusion injury (17). In general, the results of the present study do not endorse these findings. The results showed that histological grading of ovarian tissue damage in a rat model of unilateral ovarian ischemia/reperfusion injury was not significantly different if curcumin was intraperitoneally administered in either a $2 \mathrm{~h}$ ischemia/2 $\mathrm{h}$ reperfusion or a $4 \mathrm{~h}$ ischemia/4 $\mathrm{h}$ reperfusion regimen. In fact, left ovary histological grade was significantly higher in the control ischemia/reperfusion subgroups (2 or $4 \mathrm{~h}$ ) and ischemia/reperfusion plus curcumin subgroups (2 or $4 \mathrm{~h}$ ) compared with the relevant sham subgroups, in which no ischemia/reperfusion was applied. In group 2 (4 h ischemia/4 h reperfusion), TAS values were significantly higher in the control ischemia/reperfusion subgroup compared with the sham and curcumin subgroups. However, there was certain agreement with the recently published study (17), which was observed when the TOS values were examined; for group 2, TOS values were significantly higher in the control subgroup compared with the sham and curcumin subgroups. The results indicate that although curcumin was effective in reduction of TOS in a $4 \mathrm{~h}$ ischemia/4 h reperfusion rat model, it had no impact on TAS status or on reduction of tissue damage as assessed by histological grading. There was also no evidence of an effect of curcumin on the NO, NOS or XO serum values.

There are various differences in the methodology of the present study compared to the study of Sak et al (17), which could have contributed to the differences in the results obtained.
One major difference is that the present study describes a unilateral model of ovarian torsion whereas the study by Sak et al (17) used a bilateral model. However, in humans the ovarian torsion is more commonly unilateral (2), making the present study a potentially more representative rat model. Serum was also measured rather than the tissue levels of the mediators, which could have affected the findings. NO levels and activity of NOS and XO, as well as TOS, TAS and histological score were measured to provide a comprehensive suite of oxidative status indicators and markers of reperfusion injury. This was a wider group of indicators compared with Sak et al (17), in which only TOS, OSI and histological score were considered. Thus, the present study could be considered to give a more complete overview of the effects of curcumin in an ischemia/reperfusion injury model. Furthermore, 2 different time periods were examined, namely $2 \mathrm{~h}$ ischemia/ $\mathrm{h}$ reperfusion and $4 \mathrm{~h}$ ischemia/4 h reperfusion as opposed to $3 \mathrm{~h}$ ischemia/3 $\mathrm{h}$ reperfusion only (17), in order to show if curcumin was more effective at different time points. This revealed a curcumin-induced decrease in TOS levels in the $4 \mathrm{~h}$ ischemia/4 $\mathrm{h}$ reperfusion group that was not observed in the $2 \mathrm{~h}$ ischemia/ $2 \mathrm{~h}$ reperfusion group.

One potential limitation of the present study was the relatively small number of animals in each subgroup. Furthermore, only one dose of curcumin, $200 \mathrm{mg} / \mathrm{kg}$, was considered; different doses of curcumin may induce different effects.

A protective role for curcumin in the reduction of ischemia/reperfusion injury has been demonstrated for multiple other organs in rat models (14-16). For example, it has been shown that curcumin had a protective antioxidant effect against injury of epithelial cells of renal tubules, thus preventing progression of renal disease (14). However, the literature is not unanimous on the protective and antioxidant effects of curcumin in ischemia/reperfusion injury. For example, in another rat study it was reported that curcumin administration has no protective effect on acute renal injury (29). The findings of a rat study on mesenteric ischemia/reperfusion injury suggested that while curcumin treatment protected the intestine and other organs in terms of histopathological findings, it had no significant effect on TAC, OSI and TOS (21). That study suggested that curcumin protects multiple organs by mechanisms beyond antioxidant properties, for example through multiple pathways mediating inflammatory cytokines, transcription factors and other 
enzymes (21). While the present study did not concur with the histological findings of Onder et al (21), it similarly indicated no significant protective effect in terms of NOS, XO, TAS and TOS values. In the present study, the TAS levels were found to be higher in the ischemia/reperfusion control subgroup of group 2 ( $4 \mathrm{~h}$ ischemia/ $4 \mathrm{~h}$ reperfusion) compared with the sham or curcumin subgroups. This suggests that curcumin did not enhance the TAS status in the ischemia-reperfusion ovaries. However, contrary to TAS status, TOS was reduced in the curcumin subgroup, suggesting that curcumin may have a more minor modulatory role on oxidative status.

Future studies should address other potential modulatory pathways that may be influenced by curcumin treatment, such as anti-inflammatory or anti-apoptotic mediator changes. For example, in a study on liver warm ischemia and reperfusion-induced combined restrictive and obstructive lung disease, a protective effect of curcumin was mediated via reduction in lung inflammation and matrix metalloprotease-9 activity (30). Other rat studies have shown a protective effect of the agents with ROS-scavenging and anti-inflammatory capacity in ovarian reperfusion injury, for example, etoricoxib (18) and hesperidin (19). Another flavonoid, quercetin, has been shown to have anti-apoptotic effects in a rat model of ovarian ischemia-reperfusion injury (20).

In conclusion, irrespective of previous studies, the present study does not suggest that curcumin has a significant protective role in terms of reperfusion injury in rat ovaries. However, the observation that curcumin was effective in the reduction of TOS levels in a $4 \mathrm{~h}$ ischemia/4 h reperfusion model suggests that it may have certain minor effects that could be worthy of further consideration. Further extended qualitative and quantitative studies, involving greater numbers of animals, different dosages and timing of curcumin intervention, and measurement of mediators of other potentially relevant pathways, are required to further address the controversy of whether curcumin has any protective effect in ovarian ischemia/reperfusion injury.

\section{References}

1. Hibbard LT: Adnexal torsion. Am J Obstet Gynecol 152: 456-461, 1985.

2. Sasaki KJ and Miller CE: Adnexal torsion: Review of the literature. J Minim Invasive Gynecol 21: 196-202, 2014.

3. Wilkinson C and Sanderson A: Adnexal torsion - a multimodality imaging review. Clin Radiol 67: 476-483, 2012.

4. Sayyah-Melli M, Rashidi MR,Kaseb-Ganeh M,Rashtchizadeh N, Taghavi S, Ouladsahebmadarek E and Ghojazadeh M: The effect of erythropoietin against oxidative damage associated with reperfusion following ovarian detorsion. Eur J Obstet Gynecol Reprod Biol 162: 182-186, 2012.

5. Ingec M, Isaoglu U, Yilmaz M, Calik M, Polat B, Alp HH, Kurt A, Gundogdu C and Suleyman H: Prevention of ischemia-reperfusion injury in rat ovarian tissue with the on-off method. J Physiol Pharmacol 62: 575-582, 2011.

6. Osmanağaoğlu MA, Kesim M, Yuluğ E, Menteşe A and Karahan SC: Ovarian-protective effects of clotrimazole on ovarian ischemia/reperfusion injury in a rat ovarian-torsion model. Gynecol Obstet Invest 74: 125-130, 2012

7. Ozkisacik S, Yazici M, Gursoy H and Culhaci N: Does gradual detorsion protect the ovary against ischemia-reperfusion injury in rats? Pediatr Surg Int 30: 437-440, 2014.

8. Perrelli MG, Pagliaro P and Penna C: Ischemia/reperfusion injury and cardioprotective mechanisms: Role of mitochondria and reactive oxygen species. World J Cardiol 3: 186-200, 2011.

9. Trujillo J, Chirino YI, Molina-Jijón E, Andérica-Romero AC, Tapia E and Pedraza-Chaverrí J: Renoprotective effect of the antioxidant curcumin: Recent findings. Redox Biol 1: 448-456, 2013.
10. Du P, Tang HY, Li X, Lin HJ, Peng WF, Ma Y, Fan W and Wang X: Anticonvulsive and antioxidant effects of curcumin on pilocarpine-induced seizures in rats. Chin Med J (Engl) 125: 1975-1979, 2012

11. Meng B, Li J and Cao H: Antioxidant and antiinflammatory activities of curcumin on diabetes mellitus and its complications. Curr Pharm Des 19: 2101-2113, 2013.

12. Tawfik SS, Abouelella AM and Shahein YE: Curcumin protection activities against $\gamma$-rays-induced molecular and biochemical lesions. BMC Res Notes 6: 375, 2013.

13. González-Reyes S, Guzmán-Beltrán S, Medina-Campos ON and Pedraza-Chaverri J: Curcumin pretreatment induces Nrf2 and an antioxidant response and prevents hemin-induced toxicity in primary cultures of cerebellar granule neurons of rats. Oxid Med Cell Longev 2013: 801418, 2013.

14. Chen TH, Yang YC, Wang JC and Wang JJ: Curcumin treatment protects against renal ischemia and reperfusion injury-induced cardiac dysfunction and myocardial injury. Transplant Proc 45: 3546-3549, 2013

15. Aydin MS, Caliskan A, Kocarslan A, Kocarslan S, Yildiz A, Günay S, Savik E, Hazar A and Yalcin F: Intraperitoneal curcumin decreased lung, renal and heart injury in abdominal aorta ischemia/reperfusion model in rat. Int J Surg 12: 601-605, 2014.

16. Liu L, Zhang W, Wang L, Li Y, Tan B, Lu X, Deng Y, Zhang Y, Guo X, Mu J, et al: Curcumin prevents cerebral ischemia reperfusion injury via increase of mitochondrial biogenesis. Neurochem Res 39: 1322-1331, 2014.

17. Sak ME, Soydinc HE, Sak S, Evsen MS, Alabalik U, Akdemir $\mathrm{F}$ and Gul T: The protective effect of curcumin on ischemia-reperfusion injury in rat ovary. Int J Surg 11: 967-970, 2013

18. Yapca OE, Turan MI, Yilmaz I, Salman S, Gulapoglu M and Suleyman H: Benefits of the antioxidant and anti-inflammatory activity of etoricoxib in the prevention of ovarian ischemia/reperfusion injury induced experimentally in rats. J Obstet Gynaecol Res 40: 1674-1679, 2014.

19. Cakir Gungor AN, Gencer M, Karaca T, Hacivelioglu S, Uysal A Korkmaz F, Demirtas S and Cosar E: The effect of hesperetin on ischemia-reperfusion injury in rat ovary. Arch Gynecol Obstet 290: 763-769, 2014.

20. Gencer M, Karaca T, Güngör AN, Hacıvelioğlu SÖ, Demirtaş S, Turkon H, Uysal A, Korkmaz F, Coşar E and Hancı V: The protective effect of quercetin on IMA levels and apoptosis in experimental ovarian ischemia-reperfusion injury. Eur J Obstet Gynecol Reprod Biol 177: 135-140, 2014.

21. Onder A, Kapan M, Gümüş M, Yüksel H, Böyük A, Alp H, Başarili MK and Firat U: The protective effects of curcumin on intestine and remote organs against mesenteric ischemia/reperfusion injury. Turk J Gastroenterol 23: 141-147, 2012.

22. Nurullahoglu-Atalik KE, Okudan N, Belviranli M, Gokbel H, $\mathrm{Oz} \mathrm{M}$ and Esen $\mathrm{H}$ : Role of curcumin in mesenteric ischemia-reperfusion injury in rats. Bratisl Lek Listy 113: 465-470, 2012.

23. Erel O: A novel automated direct measurement method for total antioxidant capacity using a new generation, more stable ABTS radical cation. Clin Biochem 37: 277-285, 2004.

24. Verit FF, Verit A, Kocyigit A, Ciftci H, Celik H and Koksal M: No increase in sperm DNA damage and seminal oxidative stress in patients with idiopathic infertility. Arch Gynecol Obstet 274: 339-344, 2006.

25. Erel O: A new automated colorimetric method for measuring total oxidant status. Clin Biochem 38: 1103-1111, 2005.

26. Durak I, Kavutcu M, Kaçaz M, Avci A, Horasanli E, Dikmen B, Cimen MY and Oztürk HS: Effects of isoflurane on nitric oxide metabolism and oxidant status of guinea pig myocardium. Acta Anaesthesiol Scand 45: 119-122, 2001

27. Ridnour LA, Sim JE, Hayward MA, Wink DA, Martin SM, Buettner GR and Spitz DR: A spectrophotometric method for the direct detection and quantitation of nitric oxide, nitrite, and nitrate in cell culture media. Anal Biochem 281: 223-229, 2000.

28. Hashimoto S: A new spectrophotometric assay method of xanthine oxidase in crude tissue homogenate. Anal Biochem 62: 426-435, 1974.

29. Hammad FT, Al-Salam S and Lubbad L: Curcumin provides incomplete protection of the kidney in ischemia reperfusion injury. Physiol Res 61: 503-511, 2012.

30. Wu NC and Wang JJ: Curcumin attenuates liver warm ischemia and reperfusion-induced combined restrictive and obstructive lung disease by reducing matrix metalloprotease 9 activity. Transplant Proc 46: 1135-1138, 2014. 